\title{
A Revisionist History Of Accounting: From The Origins Of Private Property To Venice In The Pacioli Era
}

James H. Baskett (E-Mail:jbaskett@beta.loyno.edu), Loyola University of New Orleans

\begin{abstract}
This treatise takes a fresh (and somewhat contrarian) look at the long history of accounting leading up to the time of Luca Pacioli, who has long been considered the "father of accounting." It first examines the centuries immediately preceding the time at which Pacioli recorded the Venetian technique of double-entry bookkeeping, in order to reveal why the model appeared in Italy during the fifteenth century. It also addresses the manner in which Pacioli's work misdirected accounting historians' efforts as they have sought the origins of accounting. Secondly, this treatise looks at stimuli explaining probable origins of accounting in earliest sedentary human cultures, in order to separate origins of accounting activity from the origins of bookkeeping. It is posited not only that the dawn of the institution of private property was the sole requirement for the existence of accounting activity, but that many of the factors (including writing and formalized mathematical systems) often believed to be necessary prerequisites for accountancy are most likely consequences of, not prerequisites to, the accounting process. This treatise concentrates attention on accounting for privately-owned entities rather than governmental accounting issues, partly because Pacioli himself concentrated on that aspect of accounting, but most importantly because everything said herein regarding fundamentals of accountancy is equally valid, with appropriate modifications, for governmental and nonprofit entities.
\end{abstract}

\section{Bookkeeping in Renaissance Italy}

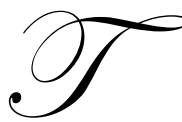

he accounting discipline was on an uneven evolutionary path spanning thousands of years before Luca Pacioli recorded and published the Venetian system of double-entry bookkeeping. The years leading up to Pacioli's celebrated mathematical treatise titled Summa de Arithmetica, Geometria, Proportioni et Proportionalita (published in 1493 A. D.) were times when bookkeeping had evolved from single-entry models to the double-entry form in which it first became known to, and published by, Luca. It appears entirely likely that the double-entry method that Pacioli called the "Venetian" model evolved within other Italian city-states in the two or more centuries before Pacioli came to reside in Venice, even though the model was clearly used in Venice and elsewhere before 1464 A. D., the year when Pacioli first arrived. As one example, a young man in Florence wrote in his diary: “ $\ldots$. On the $15^{\text {th }}$ October, 1450, I, Luca, son of Antonio [Landucci]. . . went to learn bookkeeping from a master called Calandria. Thank God that I succeeded." (Taylor, page 62) Interestingly, there is no mention by Pacioli of bookkeeping in Florence, although he had spent a great deal of time there before his sojourn in the Venetian Republic, lending credence to the idea that he first encountered it only after he traveled to Venice. The model which Pacioli set down in his Summa treatise did not appear in Venice strictly by chance, although it was by fortuitous chance that Pacioli himself was in Venice at the time he learned the double-entry paradigm. At least two important reasons for its appearance have been suggested by the scholars who have studied this epoch in history, each contributing importantly to the model which is now ascribed to Pacioli.

Readers with comments or questions are encouraged to contact the author via email. 
One influence on bookkeeping came from a learned traveler, Leonardo da Pisa (Fibonacci), an Italian who was knowledgeable about the Arabic language as well as the Arabic numeral system and algebra. His widespread travels in the Mediterranean had also led him to understand commercial practices then in use throughout the region. Leonardo wrote an important book, Liber abaci [sic.], at the beginning of the thirteenth century. Leonardo's Liber abaci and other of his works are important because through them he is credited with introducing Arabic numerals and algebra to Italy. Although da Pisa's works did not lead to widespread use of Arabic numerals for centuries afterwards, Pacioli was quite familiar with the writings of da Pisa, so that Luca himself became a leading proponent of the use of Arabic numerals in his own era. Leonardo's work was reinforced by Jordanus Nemorarius, a man who was general of the Dominican Order. His books on mathematics, including algebra, were in widespread use for more than three hundred years before Pacioli's time, and Pacioli was familiar with his works as well as those of da Pisa, whose books had been virtually forgotten (Taylor, pages $186-87$ et passim).

While Pacioli readily credits da Pisa's works as the primary inspiration for his Summa treatise, he tellingly does not speak in that work or elsewhere of da Pisa as being a primary source for his knowledge of the double-entry system. Some scholars believe that Arabs had utilized double-entry bookkeeping even before di Pisa's time, so that da Pisa might have learned the system, passed it on, and so became a conduit to Pacioli. (Macve, page 11). Countervailing evidence exists, however, in the words of Pacioli himself, who stated in the Summa that "This treatise will adopt the system used in Venice, which is certainly to be recommended above all others ...." (Quoted in Taylor, page 62) That Pacioli considered the technique as being a Venetian system suggests that, if da Pisa had written of the technique, Pacioli was not aware of it. Pacioli, however, was an ardent student of da Pisa's, which implies he would most likely have known of any written contributions made by da Pisa to bookkeeping. While evidence of Da Pisa's knowledge of bookkeeping remains elusive, he might deserve credit as the true father of bookkeeping due solely to his influence in introducing Arabic mathematical techniques to Italy, as the ease of use of the Arabic notation might have greatly accelerated an inevitable trend toward double-entry techniques. There remains the possibility that a scholar might yet be able to uncover unknown writings of da Pisa as might be found in the Vatican collection of early documents, or else in other collections somewhere in Italy, so the mystery of his bookkeeping publications might yet be susceptible to solution.

Another important influence involves the Venetian Republic itself. Venice is known to have been in existence in the $9^{\text {th }}$ century or before, but finally reached the height of her power in the fifteenth century. (Columbia, p. 2875) In that century, the city had become a thriving commercial center, having perhaps 150,000 inhabitants when Pacioli arrived (Taylor, page 44). The political infrastructure of the Venetian Republic was well developed, including strict regulations for the many guilds which existed, while taxes were being levied upon commerce. The location of Venice was strategic commercially, because she was in a direct path for east-west trade. The Venetian Republic had come to control mountain passes which led to northern Europe, and use of Venice by merchants allowed them to avoid confrontations with pirates to the west, who were subdued by the Venetian navy, and to avoid a more circuitous route to central European markets. Venice was also strategically placed relative to the region to the north because of the necessity for salt trade. As her importance in this trade flow increased, Venice was able to negotiate trade and other concessions in the cities of the eastern Mediterranean (the Levant). For example, she was able to require that ships offload more than half their merchandise in Venice before they were allowed to embark on a return voyage, and most trade was eventually required to include Venetian ships. The Venetians defeated Genoa in 1380 A. D., becoming the undisputed European sea power. As a result of these factors, Venice became a renowned shipbuilding center, and grew to be politically important, being represented by its ambassadors throughout the developed world.

A thriving business class came into existence, and Venetians continued the Italian bent towards partnerships, joint ventures and other relatively large-scale private enterprises. Commerce itself was the foundation for Venetian wealth, and it is certain that double-entry bookkeeping was well established in practice before Pacioli arrived. Indeed, commerce had become so sophisticated in Venice, and ownership interests so diverse, that conditions had been ripe for someone to have devised a set of rules for double-entry bookkeeping. As it turns out, that development did not spontaneously occur in Venice, but only because double-entry had evolved and was in use elsewhere long before Pacioli went to Venice. (Emmett R. Miller, pages 60-76) De Roover indicates that: “As early as 1277 , a company of Sienese merchants kept . . . at least six or seven books among which were a ledger, a 
cash book, and a libro dei chapitali (book of capitals) which contained the accounts of the partners and the principal employees." (De Roover, page 147) In addition, a company of merchant bankers called the Peruzzi had a network of branches in various sites in Western Europe and the Near East; although they went bankrupt in 1343, a great number of books were kept in the central office and in the various branches. Among these books was a general ledger and a book called a libro segreto 1saz, containing accounts of the partners and the branch managers. (Ibid.) In records of a fourteenth-century merchant named Francisco Datini, the ledger was separated into two parts, with the first part being reserved for accounts with a debit balance and the second part for all that carried a credit balance. Datini first kept books using single-entry book-keeping, but over the course of his business career he adopted the double-entry system. This is apparent because he finally expanded the number of accounts he used, then referred to a counterpart in another account as would be used with a double-entry system. He also began at some point to gather information in the ledger which had previously been scattered in his books. ( $\underline{O p}$. Cit., page 146)

This bent toward more sophisticated bookkeeping is not surprising, because oceangoing commerce, and other business such as banking and manufacturing, had become large-scale in several of the Italian states. The resulting diversity of ownership as would exist in a partnership or joint venture begged for a model which explicitly matched the aggregate asset value of an enterprise with the value of the various legal claims against those assets. That matching, or equilibrium condition, is the sine qua non of accountancy, and it is that which the double-entry system purports to proxy. The fact that merchants in other Italian states were keeping careful records of equity interests indicates that business ownership had evolved to this plateau. Single-entry models of bookkeeping do the same thing, although the value of legal claims against entity assets is implicitly assumed equal to the value of those assets, but not kept as a separate set of records. So long as equity interests were concentrated in individuals or in a few family members, or when other claimants were able to keep requisite control over the asset base, it might have been acceptable to count assets from time to time (i.e., periodically), value (appraise) those assets, and hence implicitly verify the interests of legal claimants against those assets. When, however, commerce became more geographically diverse, a factor requiring more complex claims on assets, an evolution to the double-entry model became inevitable, just as it would have done, given similar economic development, at any such juncture in history. That is why evidence of ownership records being kept long before Pacioli's time in the Italian city states and Venice in particular is so instructive: It manifests an evolving attempt to match assets against legal claims on a continuous basis rather than a periodic basis, a development dictating that double-entry bookkeeping could no longer be avoided.

The identity of the originator of the double-entry bookkeeping manuscript that guided Pacioli is lost in history, but merchants in Italy had certainly gravitated to its use before Pacioli's tenure in Venice. De Roover, a respected accounting historian, disagrees with other historians who suppose that the Arabs introduced double-entry methods, thinking instead that double-entry evolved in Genoa, sometime around 1340 A. D., as a response to economic conditions within Italian commercial cities following the end of the Middle Ages (De Roover, page 144). He might well be correct in this assertion, because independent evidence (as discussed above) shows a clear evolution of bookkeeping within the Italian States toward the model, indicating that it did not spring full blown into existence from a foreign source. It clearly could not have come from other European countries, because they ultimately learned the double-entry technique from Pacioli. Whatever happened in this regard, da Pisa's contributions were of highest importance to the accounting discipline because the Arabic system of notation was much more conducive to record-keeping than the system of Roman numerals. Certainly, da Pisa's work did include important algebraic information and probably introduced Pacioli and others to the new Arabic mathematical notation, factors which are sufficient to cause da Pisa to occupy an important niche in the evolution of double-entry. The fact that Pacioli finally came to be regarded as the best mathematics teacher of his era, as well as becoming an early advocate of the use of the Arabic mathematical notation, quite likely because of da Pisa's influence, lends credence to this idea. (Taylor, pages 16; 61) Ultimately, there are at least three candidates other than Pacioli who might be entitled to be remembered as the "father of double-entry bookkeeping": The unknown person(s) who first penetrated the veil of double-entry bookkeeping and implemented it in a business setting; the unknown first person to commit the technique to writing; and Leonardo da Pisa. To be fair to the individual among these most deserving of credit, Pacioli should probably be thought of as the "disciple of Venetian bookkeeping" rather than as the "father of double-entry bookkeeping" or as the "father of accounting" as he has been known for more than five hundred years. 


\section{Pacioli and the Misdirection in Accountancy}

A confluence of factors in Pacioli's life led him to Venice to become the right person to publish the Venetian bookkeeping system in a cohesive way. He was, as one example, an excellent student who displayed an extraordinary memory (He is believed to have virtually memorized the Bible). His parents apprenticed him as a young boy to a family in his home city, where he was ostensibly learning some type of business or trade. (Taylor, p. 15) Later during his youth, he came into contact with and favorably impressed Piero della Frandesca, a famous artist who also had a strong interest in pure mathematics. Pacioli is known to have studied mathematics with Piero, and it might have been he who first introduced Luca to da Pisa's contributions. In addition, Piero had been commissioned to paint in Urbino in the Urbino Duchy, and he often took Pacioli there, where Luca met Count Federigo da Urbino, a man who had assembled one of the finest libraries of Europe (This was perhaps the finest library in all of Italy-It was eventually acquired by the Vatican). While there with Piero, Pacioli had access to the library, had time to browse through it, and used it extensively. Luca also became acquainted with the father of the artist Raphael and was a friend of Bramante, a youth who later became a well-known Italian architect. Through Piero, Pacioli also met Leon Battisti Alberti, a famous architect who offered Pacioli a place to stay in Venice.

Once in Venice, Pacioli obtained a position as tutor for three sons (believed to be 14 to 18 years of age ) of a wealthy merchant, Ser Antonio de Rompiasi, moving into the Rompiasi household. Luca was expected to teach the sons not only classics, but mathematics and other skills (likely including bookkeeping) necessary for them to enter the family business. Pacioli continued his own educational advancement while in Venice, formally studying algebra and geometry as well as the humanities, but his primary responsibility was to study business and to assist in the commerce of his employer, then to pass his knowledge to the Rompiasi brothers. Interestingly, Pacioli in later years identified that year of 1464 A. D. as the year he began his career in mathematics, and it seems likely that what he referred to included not only the pure math he taught to the Rompiasi sons, but to business math as well. By the time he wrote the bookkeeping portion of the Summa around thirty years afterwards, he had achieved recognition as the leading mathematics teacher in Italy. It is most likely that, at this point in his education, he first encountered bookkeeping methods being used by Venetian merchants, including double-entry techniques. (Taylor, pages 20 - 63) It is easy to imagine that the first Venetian bookkeeping manuscript he encountered was presented to Luca by Rompiasi himself or by one of Rompiasi's bookkeepers. The place where the first double-entry manuscript was first written is not known, and probably unknowable, but Luca himself probably assumed any such manuscript was not only first written in Venice, but that the technique of double-entry had evolved there. Just what innovations or improvements Venetian bookkeepers (and Pacioli) might have made to the double-entry model remains unknown, but the large-scale commerce that had evolved in Venice, combined with complex ownership interests, was certainly conducive to using and improving the method. Had it not been previously hit upon elsewhere in Italy, double-entry might have developed de novo in Venice itself.

Pacioli's status in the de Rompiasi household was fortuitous for the accounting profession. First, Pacioli was just the right non-merchant, non-bookkeeping individual to be able to decipher the double-entry model because of his aptitude for diverse learning and avid scholarship in math. Also, unlike many scholars of the classics, he was willing to participate in, and take an interest in, commercial activities. For his part, Pacioli's intellectual curiosity and expertise in mathematics allowed him to understand the basic equilibrium nature of the bookkeeping process, then to be able to describe it coherently for a wider audience. Many others who were using the Venetian model in practice might have understood it as well as Pacioli, but none had the rounded education in mathematics Luca possessed, were probably not as literate as he, and could not have organized it as well for publication. Second, Pacioli obtained just enough business experience to have a more practical view of the world than other leading mathematicians might have had. He developed at least a limited knowledge of commerce, because he is known to have gone on commercial voyages as part of his duties during his association with the Rompiasi family. Third, Pacioli, who was an avid student with the mind-set of a great teacher, had the motivation, more than any other person of his century, to commit the bookkeeping model to writing in a publication that could be made widely available. Fortunately, he had learned to think of bookkeeping as being commercial math, explaining why he incorporated it into his Summa, which was principally a mathematical treatise. 
In committing to writing what was likely a commonplace practice among Venetian merchants, his focus was on the precise manner in which bookkeeping entries were required to be made. Since, of course, he had not known the bookkeeping vocabulary of the kind merchants were using in Venice, he most likely adopted some or all of theirs. Pacioli's focus, while forming the basis for what bookkeepers the world over practice to the present day, also entailed unwanted consequences that continue to haunt the accounting profession. Although bookkeeping terms being used in Venice probably had the appropriate connotation to merchants and bookkeepers, Pacioli's translation of these terms has misdirected our understanding of what is being accomplished within the context of accounting.

His terms "debito" and "credito," which indicate "leftness" and "rightness" according to some present-day authors, or "what is owed" and "what is owned" by others, do not reflect the economic reality of the model Pacioli published. Pacioli himself manifests a misunderstanding of these words when he says: "There are two words or expressions necessary in the keeping of a Journal, words which are used according to the custom of the great City of Venice. The one is called 'Per' and the other is called 'A.' 'Per' indicates debtor (debitore) and 'A' denotes the creditor (creditore)." (Taylor, p. 69; translated from a copy of the Summa in the Newberry Library in Chicago) It was Pacioli's choice of translation for these terms which have caused a continuing problem for all accountants succeeding him. A more realistic translation, and one which is more nearly in tune with the fundamental nature of accounting, would be to translate the term "A" as "From," indicating "a source of entity resources to fuel an economic event" and the term "Per" as "To," meaning "a simultaneous disposition, or use, of those resources." The best possible translation, however, is the one that is right in line with what occurs within every economic event: The term " $\mathrm{A}$ " means "Uses of entity resources," and the term "Per" means "Sources of entity resources." That Pacioli misinterpreted the "Per" and "A" terms might be explained in part by the fact that the polyglot language used in Venice at the time of his arrival was not what he had been accustomed to.

Bookkeeping is of value not only because it details debtor and creditor information, but because it keeps a continual record of economic events which affect an accounting entity. An "economic event" is one that affects the amount or composition of value within an entity, and one for which value impacts can be measured or reasonably estimated. Each economic event (whether explicit and implicit) in the life of an accounting entity has a dual nature, containing within it a source of resources (as fuel to allow the event to occur) and a disposition (or use of) of the same resources. A double-entry bookkeeping system represents an attempt to proxy the dual nature of all such events. What is important to realize, however, is that sources of entity resources for a particular event do not have to come from "creditors" (i.e. from owners' or creditors' equity in assets), and uses do not have to manifest an increase in entity debt, although each of these often occurs. It is entirely true that the aggregate of all transactions at any point in time as measured in an entity balance sheet represents a summary of all sources and uses, or legal claims and corresponding assets, but that does not itself dictate that every economic event increases or decreases legal claims against assets while changing the aggregate value of assets correspondingly. That Pacioli might have mistakenly thought so is understandable, because he was attempting to understand an extant manuscript intended to portray bookkeeping techniques, but most likely had never used the techniques described therein in practice.

The belief that "debit" might mean "left" and that "credit" might mean right, and that these terms have no other meaning, is, of course, patent nonsense, despite the fact that some present-day authors continue to allege so. The fact that a particular choice has been made about how to record accounting information for bookkeeping purposes (i.e., debits recorded before credits in the leftmost column and credits after debits in the rightmost column) does not mean that such format is required. Italian merchants could have elected to reverse this order without any loss in bookkeeping effectiveness. They could also make accounting entries vertically, or put the debits in one book of original entry and credits on another. We could even call debits "sheep" and credits "fodder" without altering the economic content of a bookkeeping model. To call them "uses" and "sources" would, however, have the singular advantage that these terms accurately describe the economic content of economic events. That said, the method, and its terminology, that had evolved before Pacioli's residence in Venice is acceptable, provided only that accountants recognize the temporal nature of chosen terminology, thereby refusing to be misled as to the economic meaning of what are called "debits" and "credits."

Accountants must recognize that there is only one inviolable, primal rule in accounting, and hence in double-entry bookkeeping, that every economic event must be recorded so that immediately before and after the re- 
cordation, the value of aggregate assets of an economic entity must be precisely equal to the value of aggregate legal claims against those assets. This is the equilibrium requirement of accounting entities, and it is the source of commonality for accounting systems in all times and places. While it would be nice if each economic event so recorded were correctly measured in value, correctness is not a primal requirement of double-entry bookkeeping, because bookkeeping models themselves will work even if recorded values are incorrect. As a separable matter, any of the purely bookkeeping rules of recordation we have come to accept can be violated or changed, and the terminology we might choose in our book-keeping models matters not a whit (as long as we all agree to them), but equilibrium is inviolable, the sine qua non of all accounting systems worldwide. That Pacioli did not specifically allude to (or not possibly understand) this primal fact of accountancy has spawned confusion that has led accountants right up to the present day to harbor misunderstanding as to the economic foundation of bookkeeping.

In fact, the loss of connectivity between what accounting represents and what bookkeepers do has become so ingrained that many in the present time cannot distinguish bookkeeping and bookkeeping activities from the economic model of accounting from which bookkeeping derives. Modern textbook authors and accountants in all venues often reflect this failure. They have come to focus on the terminology and technique of the double-entry bookkeeping model as we have amended it since Pacioli's time, but have lost sight of what bookkeeping is intended to proxy. Accountants also seem somewhat oblivious to the fact that single-entry models of bookkeeping are designed to accomplish just what double-entry models do. The long-standing preoccupation with bookkeeping has resulted in unfortunate consequences for the accounting profession worldwide, because it has set us upon a course of confusion which not only affects present-day accounting practice, but has caused accounting historians in particular to seek the origin of accounting by looking for the origin of the practice of bookkeeping, and not the reverse. This treatise will reinterpret evolution of the history of accounting to show that the type of business environment in which economic activity occurred eventually dictated an evolution to the double-entry bookkeeping model, but only after thousands of years during which records were kept, but double-entry was not needed.

\section{Record-Keeping in Early Sedentary Societies}

A short treatise from the Association of Chartered Accountants in the United States entitled "Ancient Accounting: Dawn of Man Through Pacioli," identifies several factors called "key ingredients" leading to the development of accounting [sic. Should read "bookkeeping"]. Among these are systems of writing, arithmetic, money, private property, credit, capital and commerce. (Association, page 1) In a separate treatise by a well-known accounting historian, it is said that "Three factors seem to have contributed to the development of accounting [sic. Should read "bookkeeping"] credit, partnership, and agency." (De Roover, page 144) It is obvious that evidence of many of the items listed would be discernable only through written records, and it is for this reason that historians have set out to find the earliest records of writing in order to establish the origins of accounting. However, the factors listed in the sources above manifest the commonplace confusion between accounting and bookkeeping. While each of the things in the lists above can be associated with accounting as well as its minion bookkeeping, only one item listed by the authors above guarantees that accounting activity will occur, and that is private property. All others listed by various authors are merely a consequence of the commencement of private ownership of property.

Scholars have not been able to pinpoint the time when writing was devised, but it is believed that some type of writing could have occurred as early as 6,000 B. C. Notably, where ancient writings are found and decipherable, evidence of accounting activity is also found. Such records are found independently in Egypt (Hieroglyphics); Mesopotamia (Sumerian Cuneiform); China (Pictographic); and in Mayan cultures. ( Columbia, pages 3012 -13) Stevelinck reports that "Egypt has a long accounting history. Thousands of accounting Papyri have been discovered, extending over fifteen centuries, that reveal the state of the art [i.e., bookkeeping] more than three thousand years ago, with some degree of clarity." (Stevelinck, page 1) In addition, Stevelinck indicates that clay tablets found in ancient Babylonia dating to the fifth century B. C. contain records, in the Cuneiform language of ancient Sumeria, of indebtedness, receipts and contracts (mostly leases). He further reports that, in papyri of around 3,000 B. C., records are found of food and livestock inventories, budgets, personnel records, vouchers and even journals. (Op. Cit., pages 5 - 14) Discoveries made in 1998 carbon-date hieroglyphics to around 3,300 B.C. in the Suhag Province of Egypt. These writings, on clay tablets and on the side of jars, are believed to represent record-keeping for tax purposes. (Association, page 2) The Usborne Encyclopedia of Ancient Greece reports that "The Mycenaeans 
adopted Minoan forms of writing to devise their own script [Linear B Script] . . . The results [from thousands of Linear B tablets] have not been that exciting, though, as the tablets mainly contain lists -- of livestock, farming produce, and craft items, as well as details of palace officials and their tasks." (Usborne, page 21)

Many of our accounting colleagues and other functional specialists have worked diligently to discover these early written records and to ascertain that they contain references to accounting activity. Happily, such records are replete with evidence of accounting, as indicated above. Unhappily, however, since so many historical records that were committed to writing have been lost through time, it is probably impossible to establish the precise era in which cohesive writing, mathematical and bookkeeping systems began to prevail, and hence to discover the first written evidence of accounting activity. The following passage refers to this absence of concrete evidence:

There is, however, one dark spot in the history of accounting. Although we can perceive fairly well how the double-entry system developed once the basic principle of duality and equilibrium was laid down, it is hard to understand how it [i.e., bookkeeping] came into being. As a matter of fact, specialists of the history of bookkeeping have all tried to solve the problem and to offer some satisfactory explanation. Owing to a lack of source material, these solutions, however are based mainly on conjectural reasoning rather than on factual evidence." (De Roover, page 144)

As it happens, the passage above is most important due to its reference to conjectural reasoning. It points up an important reality affecting accountancy: Since much of what pertains to the dawn of accounting activity predates written systems of communication, hence defying attempts to assemble "factual evidence," it must be understood by educated guessing or "conjecture" on the subject. We can conjecture, for example, that those who first practiced accounting thousands of years ago devised unique methods of accounting and record-keeping as a response to economic stimuli directly affecting them. Records of what these ancient practitioners were doing over great lengths of time no longer exist, however, and no amount of scholarly searching can cure this lamentable fact. In truth, accounting was first practiced without written records as we know them, during epochs in which no alphabet or system of mathematics (including algebra) existed or was necessary. Even if records existed (and could be deciphered) from the first day that writing occurred in human history, all that would be shown is that things were indeed being counted and accounted for at the time those records were made. They would not establish the earlier date when accounting activity commenced. What seems inescapable is that ephemeral records (records which have been lost or are indecipherable to us) were kept for hundreds, but probably thousands, of years before cohesive writing and mathematic systems emerged. These earliest records were motivated by the need for relevant information regarding assets and legal claims against those assets, as conjectured below:

The problems encountered by the ancients with records keeping, control and verification of financial transactions were not entirely different than our own today. Governments, in particular, had strong incentives to keep careful records of receipts and disbursements - particularly as concerns taxes. And in any society where individuals accumulated wealth [i.e., where the institution of private property existed], there was a desire by the rich to perform audits on the honesty and skill of slaves and employees entrusted with asset management. (Association, p. 1).

Efforts to uncover written records of ancient bookkeeping have led accounting historians to a preoccupation with the idea that accounting could have arisen only after the invention of systems of writing and mathematics permitted record-keeping to occur. However, accounting is dependent upon no such factors. Indeed, accounting records which must have existed in alternative form probably predated written records by thousands of years, because accounting appeared as soon as human society evolved sufficiently to create an economic stimulus for individuals to keep control of business property. Rather than questing in all the wrong places, there are several broad human cultural developments that should have absorbed the interest of those seeking the origins of accounting, but seem to have been ignored in the accounting history literature. First, humankind lived in a culture of huntergatherers through the Paleolithic and Mesolithic periods. During these epochs, private property and commerce of the kind which eventually evolved were nonexistent or severely circumscribed, so that accounting was likely little needed and hence of little consequence. Language evolved, becoming more complex throughout this and succeeding epochs. Second, humans became sedentary in the Neolithic period. This has been assumed to have been roughly from 6,000 to 2,000 B. C., but it might have been earlier, based on recent scientific observations of Otzi (or Oet- 
zi), the prehistoric "iceman" whose remains have been found frozen in the Tyrolean (Oetzinger) Alps. In this epoch, humans organized into tribal villages (and extensions thereof, becoming dependent on agriculture (farming of grain crops such as wheat and millet and domestication of animals). Being sedentary made it possible for wealth to be accumulated in a way that was impractical for nomadic hunter-gatherers, while sharing of communal wealth motivated methods for the inventory of communal property. Third, private ownership of property, and accumulation of significant levels of personal wealth by individuals, which often occurred in the Neolithic period (or subsequent Bronze Age, depending on the particular society) brought privately owned economic entities and commerce as we know them today into existence, thereby providing an economic motive as well as a need for accounting.

Cultural evolution led, after eons of time, to the development of bookkeeping, writing and mathematical systems, then finally to double-entry bookkeeping of the kind Pacioli encountered in Venice. In order to mount a prima facie case for this point of view, the following section of this treatise is presented in the form of a parable, which, even though it represents a reductio ad absurdum, might serve as the most valuable tool available for gaining insights into the origins of accounting activity and of bookkeeping. The reader should note that the parable that follows artificially compresses developments that spanned long periods into an artificially narrow time frame, solely for purposes of exposition.

\section{The Parable of the Akbleati Shepherds}

Sometime around six thousand years ago, the Akhwuhl tribe, settled in the southern or Sumerian region of a land that later became Mesopotamia, executed a retaliatory raid against the Koshiipu, a tribe occupying distant territories. The leader of the raiding party was Akrham. Akbleat, Akrham's young son, joined other tribe members in the raiding party. When the raid successfully concluded, the Akwuhlis discovered a large flock of sheep held in pens near the conquered village. The Akwuhl tribe had never domesticated animals (excepting dogs), even though wild sheep, pigs and goats killed in hunts had long been prized, so this was their first encounter with domesticated sheep. Akbleat convinced his father and other tribe members that it would be wise to drive the flock back to the Akwuhli Village, although it had been customary to return only with carcasses of animals that had been killed in hunts. Akbleat's idea was agreed to only because it would not have been feasible to carry carcasses of so many animals. Akbleat himself shepherded the flock back to the Akwuhl village, finding it surprisingly easy to keep the flock intact and on course. He was astonished at the actions of a Koshiipu dog that followed along, because it controlled the flock, preventing any animals from straying. Once the Akwuhl party returned home, many of the captured sheep were devoured in celebration of the successful raid, but, despite protests, Akhram and Akbleat insisted that a few sheep and the dog be spared for breeding.

The Akwuhl tribe had become a sedentary farming community years before, but they had never devised an alphabet or other organized system of writing. All existing tribal history had long remained anecdotal, having been passed down in the form of stories and legends by succeeding generations of individuals selected as having exceptional memories. The Akwuhl tribe had, however, a clear concept of measurement, because they had long been required to dispense communal grain stores according to tribal protocol, just as they had learned to share food during their earlier hunting-gathering period. A method had also been devised to determine the amount of grain needed in the tribal keep so that stocks would not be exhausted before the next harvest.

Experience soon taught Akbleat and other tribe members that sheep and farmers could not co-exist on tribal farming plots where wheat and millet were planted. Because of conflict with farming interests, Akbleat was forced to move with his small flock to hinterlands that were uninhabited and deemed unsuited to farming.

The flock flourished and even grew steadily, so that, within a few years, Akbleat felt himself able to support a wife and family. He married a young woman named Bakba. Within a few more years, several of Akbleat's family members were needed as shepherds, because the flock grew to a size that Akbleat and Baakba could no longer control alone. As news of Akbleat's continuing success filtered its way to other tribe members, pressure was exerted for communal sharing of animals. Akbleat steadfastly refused, agreeing instead to provide some sheep for consumption at tribal celebrations. Akbleat consoled himself with the idea that these were rental payments made fairly in exchange for his use of communal hinterlands. Nevertheless, as resentment regarding Akbleat's growing 
herd mounted within the tribe, only respect for Akwuhl kept the tribe from forcibly taking all the sheep. A clan meeting was eventually held at which it was decided that Akbleat would no longer be allowed an aliquot share of the annual grain crop or of hunting kills until he shared all the sheep communally. Akbleat agreed to forego his allotment, having already discovered he could barter for grain that had been allotted to other tribe members, giving them sheep, sheep skins or fermented milk in exchange. Akbleat had even learned that another tribe was eager to trade products made by their artisans and salt for sheep and related products.

Akrham and Belahm ( Akbleat's mother) died within a few decades, so that Akbleat became family patriarch. Many more family members, and even non-relatives, began working for Akbleat as shepherds and in other capacities. As the entourage grew, many Akwuhlis began to refer, rather derisively, to the hinterlands as "Akbleat's kingdom", thereby grudgingly accepting the idea that Akbleat held exclusive dominion over the flock. A few skirmishes between the Akwuhl tribe and the Akbleatis established that the Akbleatis had sufficient power to maintain control over a great expanse of hinterlands, requiring the Akwuhl tribe to finally accede claims to both land and sheep to the Akbleatis. Akbleat's practice of providing sheep to the tribe was discontinued, so that the Akwuhl tribe was required to barter with the Akbleatis for animals they needed. All this was a salient departure in Akwuhl tribal custom, because everything else of significant value had always been common tribal property, including all tribally controlled realty and most other property. Inevitably, Akbleat, his family, and the many others who became dependant on shepherding came to enjoy the status of a separate, and powerful, tribe.

Soon after he began caring for the growing flock, Akbleat had realized that some animals were being killed by predators. He had also learned that animals were also prone to wander off, reverting to feral status, despite the presence of shepherds and sheep dogs. He learned to control these losses through keeping most flocks relatively small, by keeping the predator population down through hunting, and by sending more shepherds and dogs with his larger flocks. After a time, Akbleat even grew to believe that one of his shepherds, cousin Akdarth, was stealing sheep while attending the flock far away from the family compound. This suspicion made it clear that a method was needed to determine both the extent of and timing of losses. Baakba devised a system by which this could be accomplished. She suggested that, whenever a flock left the compound, each animal would be passed through a narrow gate, so that exactly one pebble could be placed in a pot to represent that animal. After the count was completed, the pot with pebbles was sealed, marked with a symbol representing the shepherd in charge of the flock, then removed to Akbleat's private quarters where others were forbidden to go. When the flock was returned to the compound, exactly one pebble was removed from the pot for each sheep that passed back through the gate. Akbleat was thus able to say with assurance how many sheep had been lost (or gained) for the days or weeks the sheep were away. When losses became excessive, and no convincing evidence of their death by natural causes or predation was apparent, Akbleat was able to conclude theft had occurred. A pot was created with pebbles representing the number of sheep that were lost through theft and other causes. Harsh punishments were devised for theft and for careless neglect of duty while shepherding.

Baakba then made a second important discovery. She realized that the new counting method did not allow growth in a flock over a longer time period to be determined, because the number of pebbles in the count was continually changing throughout each year as the number of sheep in the several flocks varied. She therefore suggested that, on a chosen day just preceding the lambing season each year, that day's pot of pebbles should be matched with a second pot containing an equal number of pebbles for each flock. These second pots were sealed, then removed to a separate, secured location where they were not touched until about the same day the following year. By comparing the year-old pot with that of the count at about the same day a year later, a change in the total inventory for the year was ascertained for each flock. A third pot was created at this point that contained only pebbles representing the increment or decrement to each flock for the year-long period. This aggregated information helped reveal annual changes in sheep holdings, allowing the Akbleatis to decide how many sheep could be consumed or bartered without an unwanted diminution of the flock. Baakba and Akbleat further realized that, if they put a pebble in yet another pot each time they bartered a sheep (or equivalent value in sheep products) for grain or other products, they could determine the equivalent total number of animals traded during the same yearly time period. This information, combined with their pot representing the annual aggregate increase in the flock and a pot kept to represent their own consumption of sheep, allowed a quantification of the total growth in wealth that had occurred for each year. 
With an escalating number of pots in storage, it became necessary to code each pot in such a way that the identity and purpose of each could be determined when needed. Baatha, Akbleat and several younger clan members devised a system for labeling each of these pots so that their identities could be accurately discerned. This led them to also mark the Akbleati sheep with colors and symbols which identified them not only as being Akbleati property, but allowed them to be identified as belonging to particular flocks.

As Akbleat's herd increased, so did trading opportunities. Fortunately, Akbleat and his clan did not need money as we know it, because everything they needed was obtained from trading their animals. In fact, all value came to be measured in sheep, so sheep became the de facto currency to the Akbleatis. As surrounding tribes grew, more types of grain became available, more artisans' goods were made, so that a greater diversity of products became available for trade. As this proliferation occurred, it became necessary to standardize the price of each such product relative to ewes, so that more invention was necessary to be able to record barter ratios. One ram came to be equal in barter value to two ewes, and three lambs were considered equal to one ewe. As commerce broadened, one live ewe came to be valued at four sheepskins, and one ewe was valued at twenty small clay pots filled with fermented sheep milk or five large pots of wheat, millet or barley.

Individuals in other tribes sometimes needed sheep and sheep products before their own goods were available for bartering. As a result of this timing disparity, the Akbleatis began granting credit and keeping records of the equivalent amount of sheep each other tribe or tribe member owed them. Each debtor tribe or individual was allotted a separate pot, requiring that each pot be marked with a special symbol representing a particular debtor. The Akbeatis also incurred debt to other clans during times when they did not want to trade sheep or sheep products, yet needed certain products themselves. The Akbleat clan kept records of their indebtedness in just the way they kept all other records, by creating pots with pebbles manifesting the payables. All commercial disputes were resolved by negotiation between Akbleat and other tribal leaders.

As contents of some of the pots grew, it became clear that pebbles needed to be more carefully sized in order to reduce storage needs and time needed for counting them. Therefore, pebbles were standardized into various sizes. The largest pebbles represented ten ewes, and the smallest size just one pot of grain, or one-fifth of a ewe. This method proved somewhat confusing until each pebble ultimately came to be colored so that it was clearly identifiable as belonging to one of the standardized size groupings. At about this time, it became law that only Akbleat or his designates could create colored rocks of various denominations, with appropriate penalties meted against counterfeiters. These rocks gradually came to circulate as a medium of exchange in the purchase of sheep or other products. It even became necessary to increase the number of sizes in circulation so that smaller transactions could be accommodated. Thus, ewes as a denominator of value was replaced by pebbles representing whole sheep, multiples of sheep or fractions of sheep. Akbleat himself retained sole control over issuance of pebbles used in trade.

As the tribe grew, the Akbleati method of record-keeping spread to other clans, while the Akbleati monetary system became standard practice in other tribes as well. Finally, only those pebbles with a specialized Akbleati mark on them came to be acceptable in surrounding tribal villages, because only the Akbleatis were able to guarantee the value of their medium of exchange. Counterfeiting was added to the growing Akbleati list of punishable crimes. Over many generations that followed, a few advances improved the system, but its essence did not change. When the knowledge of metal and metallurgy finally came to the tribe, pebbles fell into disuse. Metal was itself inherently valuable, could be permanently embossed for identification purposes, and so replaced pebbles as the stuff of which money was made.

All the economic activity described above gradually led to the creation of a new cadre of individuals who spent all their time as record keepers, or scribes. These scribes devised ways to represent the things for which they kept inventories and other records. They thus further developed standardized symbols for labeling pots and communication of other relevant economic facts. Ultimately, they were forced by the dictates of growing commerce to etch economic data on clay tablets or on wood, then finally to use other media such as paper. All such records came to be enforceable as commercial documents when they were created by or witnessed by scribes. The Akbleati language of commerce evolved over many generations, greatly simplifying the manner in which records of economic activity were kept. In this manner, not only did record-keeping grow out of the need for accounting recordation and 
control, but impetus for standardized language and number systems evolved out of the need to account for economic events. The Akbleati system of commercial notation was combined with symbols from other tribes, all of which finally gave rise to cuneiform writing, a system that was then expanded so that even tribal myths and heroic stories of the past and present could be recorded.

Continued success led succeeding generations of Akbleatis to become the most influential tribe in a wide region of Sumeria. Surrounding tribes joined the Akbleati confederation either by choice or by conquest. At some point, one of Akbleat's descendants even inter-married with the Bakhewe family, one that had come to be considered as royalty, whereupon Akbleatis became de facto rulers of an even larger region within southern Mesopotamia.

\section{Lessons From the Akbleati Parable}

Fundamentally, the Akbleati clan needed information that parallels what we would need in a similar venture at present, and their intended result was the same as ours. This is because economic activity dictates the kinds of records that are necessary, and business people from the time of the Akbleatis forward have always responded to the call of economic necessity. It was economic events relating to privately-held property which gave rise to the Akbleati accounting for assets, and it was accounting which gave rise to the need for record-keeping (which the Akbleatis might have thought of as "potkeeping"), or "bookkeeping" as Pacioli came to know it millennia later.

While historians tend to think of accounting as awaiting the invention of written numbers or an alphabet, writing was not necessary to stimulate ancient business persons to begin accounting, because record-keeping is a fundamental, inescapable result of economic activity within the institution of private property. "Assets" is a term which by its nature implies property ownership, and those who own or control assets have strong economic incentives to measure them for owner(s), thereby recognizing that legal claims can be no more or no less than the value of owned assets. This most profound insight into the accounting process was one which was likely intuitively known even to those, like the Akbleatis, who engaged in prehistoric agriculture or craft production. While the manner of such recordation and processing of economic data certainly varied by society, the underlying result has been fundamentally the same at all times and all places in human history, because this dual aspect, or precise matching of the value of entity assets and legal claims against entity assets, is the sine qua non of all accountancy. It would exist even if private property existed and no discernable records were kept, because accounting is more fundamentally economic than is its manifestation through record-keeping.

The Akbleati experience reveals that an alphabet and a system of mathematics are nice, but not necessary, tools for accountancy. When our historical curiosity leads us to examine the earliest of bookkeeping records, that is fine, provided we do not lose sight of the fact that thousands of years of Akbleati-like accounting record-keeping that occurred will never be found ( or if found, not susceptible to being deciphered), preventing origins of accounting activity and bookkeeping records from being mapped on a one-to-one basis. In fact, economic, and hence accounting, activity not unlike Akbleati record-keeping, likely occurred for millennia of sedentary civilization before a cohesive system of alphabetic recordation came to exist that would have allowed record-keeping to become bookkeeping in the modern sense. Further, there is an economic motive to create standardized record-keeping symbols that might logically furnish the foundation and inspiration for a writing system. In fact, systems of writing and mathematics can be reasonably conjectured to have evolved out of accounting activity, while an argument that the reverse occurred would be difficult to mount.

\section{Conclusion}

Accounting for private enterprises as we know it certainly began no later than the time ownership of property by individuals was recognized and enforceable by might, or by force of law or custom. Accounting is, at its core, the continuous recognition of a one-to-one mapping between such property (assets) and the legal claims against those assets. This mapping is the sine qua non of accounting. Record-keeping is the attempt to reflect this equality. Ancients who kept the earliest accounting records might have done so in a seemingly crude manner, and in a manner that we might not easily accept as "bookkeeping," but their needs for record keeping did not differ sub- 
stantially from those of modern accounting systems. Regardless of the era or the place in which the institution of private property is examined, one can find evidence of inventory, of keeping records of debt and credit, and of records used for taxation. It takes little imagination to discover the reason for such accounting activities. What would take more imagination is to suppose that any economic enterprise owned by a business person or persons would not require sufficient records for its own perpetuation as a going concern.

As the Akbleati parable suggests, a certain amount of conjecture is necessary in order to divine the true origins of accountancy. When accounting historians seek the origins of accounting, they must desist from looking for the origin of written record-keeping as the explanatory variable, because accounting existed long before written records were kept. Since the time of Pacioli, accountants have been preoccupied with the notion that bookkeeping rules are paramount, and that accounting and bookkeeping are the same thing, so that the search for the earliest existence of accounting has been misdirected accordingly. Accounting historians must come to realize that accounting and record-keeping (i.e., bookkeeping) are different things. It is likely that records of accounting activity gave rise to the need for mathematical notation and even written language, and not the reverse, as many historians seem to have believed.

Perhaps the most intriguing question of all is why it took so long for the double-entry system of bookkeeping to take hold only after passage of thousands of years of sedentary society. Certainly, the evolution of writing helped, and the Arabic numeral system (and algebra) certainly facilitated meeting the requirements of the model. However, we can envision that merchants long before the era of Renaissance Italy almost certainly pondered how it might be possible to keep records of the kind that double-entry bookkeeping accomplishes. As a group, however, merchants throughout a long span of history were likely not well educated, and often illiterate, a fact Pacioli lamented in his own era. Business activities, unlike so-called "classical" studies, were not considered worthy of serious study even in Renaissance Italy, so that those involved in business probably did not have a written source with which to gain an education in the double-entry method, even if they could intuitively conceive of its elements. Finally, the scale of commerce as it evolved in Venice and elsewhere in the Italian city-states allowed larger and more far-reaching enterprises to exist, introducing a need for double-entry methods. Other factors seem to have differentiated the Italian states from earlier societies, two of these being a well-organized system of commerce, including regulatory laws and taxation, and much more widespread availability of formal education. In Italy, the particular environment that supported a reverence for learning, culture and formal education, and that included private ownership of property combined with complex ownership of business entities, simply accelerated a trend that was inevitable, even though it had been millennia in arriving.

\section{References}

1. Association of Chartered Accountants in America. August 1, 2002. Website http://acaus.org/history/hsanc.html,, pages 1 -5. Cited as Association.

2. De Roover, Raymond. 1938. "Characteristics of Bookkeeping Before Pacioli." Accounting Review (Vol. 13: June1938) pages 144-48.

3. Pacioli, Luca. Summa de Aritmetica, Geometrica, Proportioni et Proportionaliti: Distintio Nona-Tractatus XI, Particularis de Computis et Scripturis. Translated by R. G. Brown and K. S. Johnston in Pacioli on Accounting (McGraw-Hill, 1963). Originally published in Venice, Italy in 1494 A. D.

4. Cushing, Barry E. 1989. "A Kuhnian Interpretation of the Historical Evolution of Accounting." The Accounting Historians Journal (Vol. 16, No. 2: December, 1989) pages 1 - 41.

5. Chisholm, Jan, Lisa miles and Struan Reid. 1999. The Usborne Encyclopaedia of Ancient Greece. (London, England: The Usborne Publishing, Ltd. 1999) Cited as Usborne.

6. Cronhelm, F. W. "The Principles of Equilibrium, Double Entry by Single" ( London, 1818), in Richard Brief, ed., Four Classics on the Theory of Double-Entry bookkeeping (Garland Publishing, Inc., New York) Pages 1-7.

7. Edwards, Edgar O., Bell, Philip W. and Johnson, L. Todd. 1979. Accounting for Economic Events (ScholarBook Co., Houston, TX.) Page 5.

8. Ijiri, Yuji. 1995. "The Beauty of Double-Entry Bookkeeping and its Impact on the Nature of Accounting Information." in Proceedings on the Conference Accounting and Economics in Honor of the $500^{\text {th }}$ Anni- 
versary of the Publication of Luca Pacioli's Summa de Arithmetica, Geometria, Proportioni et Proportionalita ( Garland Publishing, Inc.: New York) Pages 265-285.

9. Kohler, Eric L. 1975. A Dictionary for Accountants, fifth edition (Prentice-Hall, Inc.:Englewood Cliffs, N. J.): pages $147 ; 155$.

10. Macve, Richard H. 1996. "Pacioli's Legacy," in Accounting History From the Renaissance to the Present (Garland Publishing, Inc.: New York) Pages 3-30.

11. Pin, Antonio. 1995. "The Contribution of Luca Pacioli to the Development of Business Accounting," in Proceedings on the Conference Accounting and Economics in Honor of the 500 ${ }^{\text {th }}$ Anniversary of the Publication of Luca Pacioli's Summa de Arithmetica, Geometria, Proportioni et Proportionalita (Garland Publishing, Inc.: New York, 1995) . Pages. 161-177.

12. Shubik, Martin. "Accounting and its Relationship to General Equilibrium Theory," in Proceedings on the Conference Accounting and Economics in honor of the $500^{\text {th }}$ Anniversary of the Publication of Luca Pacioli's Summa de Arithmetica, Geometria, Proportioni et Proportionalita (Garland Publishing, Inc.: New York).Pages 226-34.

13. Stevelink, Ernest. "Accounting in Ancient Times." The Accounting Historians Journal (Volume 12, No. 1, Spring, 1985) pages. 1-16.

14. Taylor, R. Emmett. 1962. No Royal Road: Luca Pacioli and His Times (The University of North Carolina Press: Chapel Hill).

15. The New Columbia Encyclopedia, $4^{\text {th }}$ Edition. 1975 (New York: The Columbia University Press) 3052 pages. Cited as Columbia. By Backer, Morton (Prentice-Hall, Inc., New York) page 49.

16. Wheeler, John T. 1995. "Economics and Accounting," in Handbook of Modern Accounting Theory, ed. by Backer, Morton. 1955 (Prentice-Hall, Inc., New York) Page 49. 
Notes 